\title{
Combined Community/Content Environments: User Behavior and Attitudes
}

\author{
$\underline{\text { doi:10.3991/ijac.v2i1.265 }}$ \\ G. Granitzer ${ }^{1}$, K. Tochtermann ${ }^{1,2}$ \\ 1 Know-Center, Graz, Austria \\ 2 Graz University of Technology, Graz, Austria
}

\begin{abstract}
Currently, combined community/content environments gain increasing importance in different areas of life, ranging from private to educational to corporate contexts. However, since they are still a novel achievement it is not so clear how they should be organized in order of their successful operation. For gaining a deeper insight in what makes such an environment work, the authors systematically analyzed two combined community/content environments by evaluating user data and an online questionnaire covering the following areas: intensity of content consumption and production, preference of content types, information needs, motivation and trust, and importance of quality criteria. From the results a number of recommendations for providers were derived.
\end{abstract}

Index Terms-evaluation, knowledge community, success factors, virtual community

\section{INTRODUCTION}

For about three years technologies and concepts summarized under the term web 2.0 gain increasing importance. Basically, the concept web 2.0 has two natures. In the understanding of Tim O'Reilly web 2.0 refers to business models building on the eight design patterns which he defined. In the understanding of users, be it individuals or organizations, web 2.0 refers to applications which allow for social interaction, independent of the underlying business model. In this article web 2.0 is also understood in the latter sense. One of its key points - for the original definition see [1] or find a good recapitulatory description in [2] - is what is called the architecture for participation. The change of the internet in the sense of increased user participation and interaction and its effects are already graspable and web 2.0 little by little finds its way into various areas. Companies start using corresponding applications for business purposes as well as educational institutions start introducing corresponding applications for learning and teaching purposes. In the meantime a lot of research and reports have been done concerning web 2.0 in general and in special contexts such as [3], [4], [5], [6], [7] or [8]. A lot is especially said about virtual communities and what can be achieved by them [9]. Even though communities are not a novel concept and have a long history - the concept was first discussed by Tönnies in 1887 [10], with the emergence of web 2.0 they have undergone a revival in the form of virtual communities. Actually, virtual communities - for a good overview on the nature and definitions of virtual communities see e.g. [11] - can be understood as a kernel of web 2.0. There is a plethora of success stories. Wikipedia ${ }^{1}$ is the collaboratively created encyclopedia, and Salesforce ${ }^{2}$ is the prime example for a company which integrates its customers in further developing their solution. Innocentive ${ }^{3}$ functions as intermediary between companies looking for a research and development solution and experts who can provide a solution. And even traditional enterprises such as Lego 4 adopted web 2.0 applications and integrated them into their business model. The mentioned organizations utilize communities in different ways. Either groups of people create ideas or solutions in cooperation, or individuals who are part of a community create ideas or solutions by themselves. Not all, but a good number of virtual communities are successful. There have been some investigations on success factors, see e.g. [12], [13], or [14], but to the impression of the authors the derivation of guiding actions was not sufficient. For that reason the work at hand concentrated on identifying key characteristics of what we call community/content environments, namely environments which provide professional content on the one hand and community features and thus user generated content on the other hand: two such community/content environments were extensively analyzed by means of questionnaires and user data analysis and guiding actions were derived.

In the following chapter the analyzed environments are specified, followed by a description of goal and evaluation methodology. Then the results are reported. Finally, the results are condensed to key findings which are discussed in the last chapter.

\section{ANALYSIS OF COMMUNITY/CONTENT ENVIRONMENT}

\section{A. Description of analyzed environments}

The first analyzed environment was the German speaking knowledge community Alexander. This environment was set up in the context of a pilot project conducted by the Graz University of Technology Institute for Information Systems and Computer Media and the Know-Center. There were also two cooperation partners, namely media companies which provided encyclopedic and newspaper content. The official runtime of the pilot project was 5 months, from 6 September 2006 to 31 January 2007. Because of the defined beginning and end of the pilot project, now the environment is no longer accessible. However, insights flew into the so called

\footnotetext{
www.wikipedia.org

www.salesforce.com

http://www.innocentive.net/

${ }^{4}$ www.lego.com
} 
Austria Forum. In Alexander users could consume professional and user generated content as well as they could produce content which thematically was not restricted. The professional content consisted in newspaper and lexical articles provided by the two media companies. The users could ask and answer questions, create articles and suggest topics for articles. The quality was controlled by experts as well as by the users who could mutually rate contributions. Another task of the experts was to answer questions which were not answered by the community itself within two days. Users could also place advertisements in the form of an article, but they had to mark them as such. In sum, there were nearly 800 users which was the predefined upper limit. They were primarily acquired by three announcements of the newspaper partner. Even though no defined target group was addressed, the composition of users was biased by the medium where it was announced. In principle it was an open to the public, but eventually closed community.

The second analyzed environment was the German speaking Plattform Wissensmanagement ${ }^{5}$ established in 2001, which, as the name says, has its focus on knowledge management. Basically, this platform consists of an area open to the public where contents such as books, reports or links are available and a community area which registered and sustaining members can access. A variety of services is provided in this area: newly posted content can be subscribed, a web based email client is integrated, users can manage their bookmarks individually and collaboratively, profiles of other users are available and can be checked for similarities, in a forum members can discuss their issues, messages can be posted on a pin board, and search functionalities help with finding content as well as members. Similar to the above described community, Plattform Wissensmanagement provides professional content as well as user generated content. But contrary to the previous community, professional content is not offered by particular providers. Users themselves are called to suggest for example books, studies or links. However, actually this task is primarily taken over by the moderator, since community members are rarely contributing actively. On the contrary, activity within the above mentioned community services is satisfying. Target groups addressed by the platform are further education, consulting, interested practitioners, students and science. Contrary to the previously described community the current one does not only exist virtually but also physically. Regularly, meetings and events are organised. The community has a long history, it exists since 2001.

As can be seen from the above descriptions these two environments differ from each other in some concerns. While the second one is thematically focused and addresses a defined audience, the first one did not specify these aspects. Additionally, the first one was a pure virtual community, while the second one combines virtual and physical aspects. Also, the facilities for social interaction are far more developed in Plattform Wissensmanagement than they were in Alexander. However, it is exaclty those differences which help to find out common success factors: results that hold for both types might carefully be interpreted as general ones.

\section{B. Goal and evaluation method}

As it was said in the introduction the goal of our work was to find out about fundamental characteristics of community/content environments, in reference to the activities of the users, in order to derive indications for the design of a community/content environment.

For achieving this goal we analyzed the previously described community/content environments. The analysis was done by conducting questionnaires which were presented online by use of Lime Survey ${ }^{6}$, formerly PHP Surveyor. Beside some specific questions, the following areas were addressed in both cases.

- Intensity of content consumption and production

- Preference of content types and information requirements

\section{- Motivation and trust}

- Importance of quality criteria

In both cases the questionnaire was available for about one month. In case of Alexander there were 104 valid answers, corresponding to a rate of return of $15 \%$. In case of Plattform Wissensmanagement there were 73 valid answers, corresponding to a rate of return of $5 \%$. As it would have been expected the structure of the respondents was slightly different, but comparable in some aspects. About $91 \%$ of the Plattform Wissensmanagement respondents were registered or sustaining members, a majority of $82 \%$ was between 21 and 50 years of age, and the same percentage had a university degree. Also, $70 \%$ and thus the majority of the Alexander respondents were within the mentioned age range, but a by far lower percentage, namely $36 \%$ had a university degree. Indeed nearly $50 \%$ had a high school degree and presumably were students, for which reason we can conclude that both samples were well educated. The proportion male/female was identical: about three fourth of the community members was male.

\section{Results}

In the following, results are outlined alongside the before mentioned areas. In addition, some findings special to the individual environments are reported.

\section{1) Intensity of content consumption and production}

It is a well known phenomenon that usually most of the users contribute little, while some users make up the bulk of the content. The majority uses community environments passively. Only the minority actively contributes. This effect can also be found e.g. for Wikipedia $^{7}$ : So, in September 2006 there were 292.609 contributors, namely users who edited at least 10 times since they arrived, and 75.716 active wikipedians, namely users who edited at least 5 times in the given month. Also in [7] it was shown that in various web 2.0 applications the number of passive users clearly exceeds the number of active users.

In Alexander half of the users stated that they spend between 80 to 100 percent of their time with pure reading. Also the following finding goes along with this result: as regards the total activity of the users in Alexander it was found that $83 \%$ accomplished up to 50 actions, while only $15 \%$ accomplished between 50 and 500 actions. A similar

\footnotetext{
${ }^{6}$ http://www.limesurvey.org/

http://stats.wikimedia.org/EN/Sitemap.htm 
result was found for Plattform Wissensmanagement. Across different content categories, the majority of users report that they spend 80 to 100 percent of their time with pure consumption. However, as the following Figure 1 shows there is a difference. In Plattform Wissensmanagement there is a better balance of passive and active users. Nearly one third of users spend their time in actively contributing.

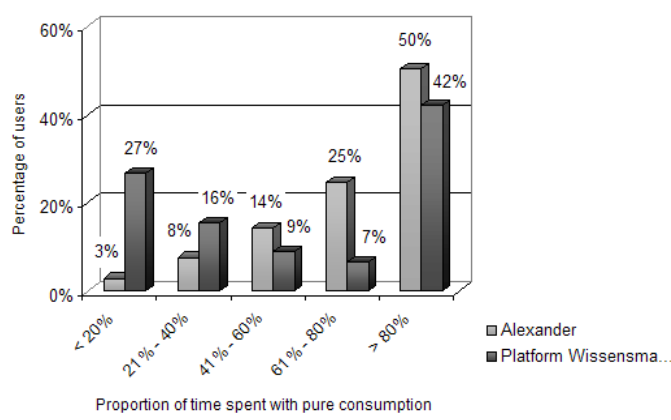

Figure 1. Percentage of users in reference to proportion of time spent with pure consumption of content

However, this proportion varies for the different content categories. Users spend about $63 \%$ of their time on average with consuming link and book tips or other professional content. As regards interactive content pure consumption is not so dominant: about $50 \%$ of the time on average is spent with pure consumption, while the other $50 \%$ are spent with actively contributing to forum discussions or posting on the pin board. Corresponding to the proportions of time spent for consuming different content categories, also in Alexander it was found that interactive content, namely questions, answers and community articles were more frequently consumed than different kinds of reading tips and newspaper articles. The average frequency of consuming community articles and questions/answers was 2.3 and $2.1^{8}$, while the average frequency for consuming lexical and newspaper contents was 3.0 and 2.8, respectively.

When looking at the frequency of using the community/content environment as such we found some difference. As regards Plattform Wissensmanagement, $84 \%$ of the users report that they use the platform $1-2$ times a month or less. The minority accesses the platform up to 1-2 times a week. As regards Alexander, 61\% of the users accessed the platform up to 1-2 times a week, while only 39\% accessed it 1-2 times a month or less.

Concerning the interaction between users in Alexander, it was found that on the whole 1.062 answers were given to 424 questions, corresponding to 2.5 answers per question on average. Most of the questions were answered by the users themselves, only $12 \%$ were answered by experts. Response time was very short: the majority of questions, namely $72 \%$, were answered within 24 hours.

\section{2) Preference of content types and information requirements}

In both environments the user was provided with various content types. On the one hand there was professional content such as newspaper articles, lexical articles, books, theses or studies. On the other hand there was user generated content reflecting individual knowledge and opinions. The question in this context is for which purposes users utilize the community/content environments. Are they interested in content, community issues, or both?

For Alexander it was found that when having concrete information requirements about half of the users preferably accounted for community content. Only 32\% thought about seeking advice in lexical articles first and only $17 \%$ looked up newspaper articles first. When asked about the frequency of consumption, 53\% and 65\% reported a frequent consumption of community generated articles and answers/questions, respectively. Only 30\% and $37 \%$ stated a frequent use of lexical and newspaper articles, respectively. In this context it is also interesting which link types were given in the community generated content. So, less than $3 \%$ of all links were links to newspaper and lexical content, but about $17 \%$ of all links were links to community content. Even though we do not have available the same data for Plattform Wissensmanagement, from an interview with the moderator we know that relatively people are more active as regards interactive community contents.

Concerning information requirements for Plattform Wissensmanagement it was found that $41 \%$ of the users have information needs related to profession and $45 \%$ of the users have information needs related to education. For Alexander similar percentages were found. 55\% of the users had information needs concerning learning and 44\% had information needs concerning profession. There is, however, a difference. Since ALEXANDER addressed no special target group, $27 \%$ of the users stated that they would consult the environment because of spare time related questions. The same was true only for $1 \%$ of the Plattform Wissensmanagement users. The lacking thematic focus of Alexander was also reflected in the variety of topics that arose during run time. Ten categories were emerging, reaching from health/medicine to politics.

\section{3) Motivation and trust}

The motives for participating in a community/content environment can be manifold: people might wish to demonstrate their power or they might have a need for proximity. Since the analyzed environments per definition were knowledge intensive, knowledge related motives were queried.

As can be seen in Figure 2, for Alexander it was found that on average the motivation for disseminating and exchanging knowledge was lower than for satisfying information needs, securing knowledge or undirected browsing. The average strength of the knowledge dissemination and exchange motive was 2.0 and 2.3, while the average strength of the information need, knowledge securing, and knowledge browsing motive was 1.5, 1.5, and 1.6, respectively. Contrary, for the Plattform Wissensmanagement user on average it is more important to disseminate and exchange knowledge, and also to satisfy information needs, than to secure or browse for knowledge in an undirected manner. The average strengths of these motives were 1.8, 1.8, 1.6, 2.3 and 2.3, respectively.

\footnotetext{
${ }^{8}$ In the questionnaire four point scales were used. They ranged from

1 ... frequent/important/strong to 4 ...not at all frequent/important/strong
} 


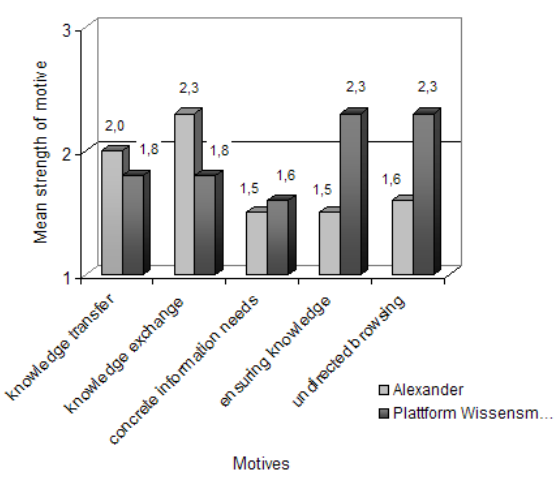

Figure 2. Motives for participating in the environments

Beside these directly addressed motives the following motives were listed by the respondents: curiosity, up-todateness and type of offered content, professionalism of environment, short response time, free of charge service.

Most Alexander users, $85 \%$ and 64\%, respectively, told that their trust in community articles was highest when the qualification of the producer is good or when he got a good evaluation. Only 5\% report that their trust was highest when the community member produced a high number of articles and $14 \%$ trusted community articles most when there is a long membership.

4) Importance of other quality criteria

Beside the content related questions it was also analyzed which other criteria were important for users in a community/content environment.

As regards quality control users of both community/content environments on average judged expert evaluation as important as user evaluation. In Alexander the average importance was 1.6 and 1.8, in Plattform Wissensmanagement it was 2.0 and 1.8 .

Concerning community generated contents, for Alexander users the correctness as regards content was of highest importance. The mean importance was 1.1. For Plattform Wissensmanagement users correctness as regards content, and also up-to-dateness were of highest importance. The mean importance was 1.2 and 1.3, respectively.

For Plattform Wissensmanagement users it was most important that goal and purpose are clear. The mean importance was 1.4. For Alexander users it was most important that there were rules of behavior. The mean importance was 1.5. However, on average all suggested conditions, namely goal and purpose, rules of behavior, expert and user quality control, were judged rather important. Across environments and criteria the mean importance only varied between 1.2 and 2.0. Among further mentioned conditions there were: quality control, easy to use system, good social forms, and transparency about members.

When asked for the conditions under which one would pay for a community/content service the following were mentioned: provision of very special, elsewhere not available content, high quality and correctness as regards content, authors getting paid for their contributions, no advertisements, elaborated payment system.

5) Further findings

In Alexander it was also asked which kind of advertisements would be accepted in a community/content environment. While $21 \%$ of the respondents would not accept advertisements at all, $72 \%$ would accept unobtrusive advertisements on the screen margin, 22\% could live with banner ads, and only 8\% could accept advertisements embedded in articles which were allowed in the Alexander environment.

Since Plattform Wissensmanagement also organizes physical events and people hence partly know each other, they were asked for the importance of these contacts: for $70 \%$ of the respondents private contacts are a reason for further utilizing the environment, while for $21 \%$ this is no reason. In that sense, $76 \%$ of the respondents stated that they were interested in the profile of other members, while $11 \%$ were not.

When asked for the channels via which people are best reachable and which hence could be used for promoting a new community, $86 \%$ mentioned the informal way, namely colleagues or friends. Articles in magazines or newspapers were mentioned by $62 \%$ and internet advertisements by $38 \%$. Promotion via television would work worst: only $1 \%$ is reachable via this channel.

\section{Interpretation}

In the following we summarize the results in form of key findings and outline what can be concluded as regards the design of a community/content environment. Of course, the authors are aware of the fact that the observed results require further validation. Anyhow, first ideas about success factors should not be kept back.

\section{1) Motivation}

Even though in both cases all knowledge intensive motives were important factors for participating in the community/content environments, in case of Plattform Wissensmanagement users it was relatively more important to disseminate and exchange knowledge than for Alexander users. Concrete information needs were a driving force in both environments. Since we do not expect that motives form the environment, we assume that such users attend whose motives are met by the environment.

From the above said we can conclude that depending on the intended purpose operators of a community/content environment should take care of which motives they address and how they design and position the environment hence. Of course, they cannot guess the motives of their audience, but they can make clear to their potential audiences which purpose the environment serves for. Thus, audiences whose motives are not addressed will abandon from participating, leaving the arena to those whose motives fit the purpose of the environment. This is expected to yield a more focused and thus effective interaction. The same is true for the target group. Defining a target group in advance might help to improve interaction.

\section{2) Trust}

Most of the Alexander users stated that their trust in community generated content was highest, if the content producer has an appropriate qualification. And the majority of Plattform Wissensmanagement users state that they were highly interested in the profiles of other users.

Since trust is a key factor for participation, it must be a major aim of a provider to ensure it. According to the respondents trust heavily depends on the qualification of a user for which reason such information should be 
provided within a community/content environment. It could be included in a profile which, as results further suggest, basically is of interest to the participants. It is assumed that knowing about the other users not only results in increased trust, but also or even as a consequence in a more focused, probably intensified and thus effective interaction. Also the suggestions in [15] point in that direction. For increasing trust in user generated content, amongst others, it is recommended to make user profiles, including for example expertise or experience, visible for the community members or to introduce possibilities for rating the contributions of other users.

\section{3) Active versus passive participation}

As it was extensively outlined in section C.1 only few users contribute a lot while the majority utilizes the environments passively.

Even though this is a common finding it is important to say that providers of community environments should make sure that either there are enough members so that the environment stays alive or there is a moderator/expert who contributes content and motivates the members. But also time has its effects: As it is stated in [8] utilization switches to interactive and participative utilization the longer a web 2.0 service is used. Moreover, it seems that if a critical mass of regularly contributing and active members has been reached the community is self sustaining. So in Alexander response time was very short: most of the questions were answered within 24 hours by the community members themselves. But this must not fuel the illusion that user participation is a matter of time or, as above mentioned, a fact of meeting motives. Providers must be aware that there will always be lurkers and that the reasons for lurking are manifold [16]. They reach from restricted time resources to the wish to remain anonymous.

\section{4) Preferred content}

As regards preference of and relative activity in different content types it was found that users appreciate community generated content and content arising from interaction very much, sometimes more than professional content.

One explanation could lie in an obviously strong need of users to interact socially. Another reason could be that community generated content better conforms concrete information needs than professional standardised content from which users must extract answers laboriously. Anyhow, cautiously it can be concluded that community features should be a standard service in an environment where content is provided. In this context it must be taken care of the quality. This can also be read from the results. Respondents emphasize the importance of correct content and judge user and expert evaluation as vital. Also, the majority trusts community generated content most if the producer has a corresponding qualification. This means that in any case providers must implement some kind of quality control.

\section{5) Further aspects}

As can be read from the further results some other aspects should be considered when designing a community/content environment.

Since users state that rules of behavior, goals and purpose of a community should be made clear, these should be introduced at the very beginning of establishing an environment. Knowing which behavior is expected and what the community serves for helps the users to orient and to contribute in a meaningful way.

Furthermore, it was shown that unobtrusive advertisements at the site margin are accepted by the majority of users. Only $21 \%$ do not accept advertisements at all. This suggests that advertisements can promptly be integrated in the community/content environment without discouraging users from participation.

\section{CONCLUSION}

By systematically analyzing the described community/content environments for how and why users utilized them, a number of helpful recommendations for the organization of such environments were derived. Of course further detailed analyses of different kinds of communities are required, so that potential providers can be advised accordingly in their efforts in establishing such environments. Extended analyses must also include corporate community/content environments, since companies have an increasing interest in adopting web 2.0 technologies and principles for business issues.

\section{ACKNOWLEDGMENT}

The Know-Center is funded within the Austrian COMET Program - Competence Centers for Excellent Technologies - under the auspices of the Austrian Ministry of Transport, Innovation and Technology, the Austrian Ministry of Economics and Labor and by the State of Styria. COMET is managed by the Austrian Research Promotion Agency FFG.

\section{REFERENCES}

[1] T. O'Reilly, What Is Web 2.0. Design Patterns and Business Models for the Next Generation of Software. O'Reilly Media, Inc., 2005. www.oreillynet.com/pub/a/oreilly/tim/news/2005/09/30/ what-is-web-20.html, accessed January 28, 2008.

[2] H. Rollett, M. Lux, M. Strohmaier, G. Dösinger, K. Tochtermann, The Web 2.0 Way of Learning with Technologies. International Journal of Learning Technology, Vol.3. No.1, pp 87-107, 2007. (doi:10.1504/IJLT.2007.012368)

[3] M. Ebner, M. Zechner, A. Holzinger, Why is Wikipedia so successful? Experiences in establishing the principles in Higher Education. Proceedings of the 6th International Conference on Knowledge Management, September 2006.

[4] J. Pauschenwein, M. Jandl, A. Riegler, G. Vasold, How to use weblogs in eSupervision? Proceedings of the 6th International Conference on Knowledge Management, September 2006.

[5] J. Morath, Web reloaded? Driving convergence in the real world. Arthur D. Little, 2006.

[6] J.B. Horrigan, A Typology of Information and Communication Technology Users. PEW INTERNET \& AMERICAN LIFE PROJECT. John B. Horrigan, Associate Director for Research, 2007. http://www.pewinternet.org/pdfs/PIP_ICT_Typology.pdf, accessed January 28, 2008.

[7] S. Haas, T. Trump, M. Gerhards, W. Klingler, ARD/ZDF-OnlineStudie 2006. http://www.br-online.de/br-intern/medienforschung lonlinenutzung/onlinestudie/, accessed January 28, 2008.

[8] Booz Allen Hamilton: Web 2.0 - Mythos oder Realität? Marktanalyse, Pressekonferenz Frankfurt 2006.

[9] B. Gissing, K. Tochtermann, Corporate Web 2.0. Web 2.0 und Unternehmen - Wie passt das zusammen? Shaker Verlag 2007.

[10] F. Tönnies, Gemeinschaft und Gesellschaft. Grundbegriffe der reinen Soziologie. Wissenschaftliche Buchgesellschaft, 2005.

[11] N. Fremuth, A. Tasch, A. Virtuelle und mobile Communities. Begriffserklärungen und Implikationen für Geschäftsmodelle. Arbeitsberichte des Lehrstuhls für Allgemeine und Industrielle 
Betriebswirtschaftslehre an der Technischen Universität München., 2002. http://www.cosmos-community.org/download Files/WP035.pdf, accessed January 28. 2008.

[12] Leimeister, J.M., Sidiras, P., Krcmar, H. (2003). Erfolgsfaktoren virtueller Gemeinschaften aus Sicht von Mitgliedern und Betreibern - Eine empirische Untersuchung. Proceedings der 6. Internationalen Tagung Wirtschaftsinformatik 2003. Medien Märkte - Mobilität. Uhr, W., Esswein, W., Schoop, E. (Hrsg.). Band 2. Heidelberg. 2003. Physika-Verlag. 659-680. ISBN 37908-01119. http://wwwkrcmar.in.tum.de/lehrstuhl/publikat.nsf/ intern01/4402AFE834658B9DC1256DCE0029EF3B/\$FILE/0327.pdf, accessed January 28, 2008.

[13] Gannon-Leary, Patricia Margaret \& Fontainha, Elsa (2007). Communities of Practice and virtual learning communities: benefits, barriers and success factors. eLearning Papers, no. 5. ISSN 1887-1542.

[14] Main Critical Success Factors for the Establishment and Operation of Virtual Communities of Practice. Carlos Alberto HERNANDES1 and Paulo Sérgio FRESNEDA2. 3rd European
Knowledge Management Summer School. 7-12 Sept, 2003 San Sebastian, Spain

[15] You Who? - Trust in Web 2.0. http://www.webcredible.co.uk/ user-friendly-resources/web-credibility/web20-trust.shtml, accessed January 28, 2008

[16] B. Nonnecke, J. Preece, Why Lurkers Lurk. AMCIS Conference, Boston, June 2001. http://www.ifsm.umbc.edu/ preece/ Papers/AMCISlurker.01.pdf, accessed January 28, 2008.

\section{AUTHORS}

G. Granitzer is with the Know-Center Graz, Austria (e-mail: ggrani@know-center.at).

K. Tochtermann is with the Know-Center Graz, Austria, and Graz University of Technology, Austria (email: ktochter@know-center.at).

Manuscript received 21 February 2008. Published as submitted by the authors. 